\title{
Numeral Simulation of Hall Element on the Basis of Buried Channel MOSFET
}

\author{
R.Z. Khafizov ${ }^{1}$, M.I. Pavlyuk ${ }^{2}$, A.E. Timofeev ${ }^{3}$ \\ ${ }^{1}$ GraphImpress Co Ltd, Moscow, imagelab@mail.ru \\ ${ }^{2}$ Milandr Group, Moscow \\ ${ }^{3}$ ZNTC JSC, Moscow
}

\begin{abstract}
Electro-physical parameters and characteristics of magnetic sensitivity of silicon MOSFET Hall sensor with buried channel in wide range of control potentials are studied with the help of TCAD simulation methods. Dynamics of space distribution of free carrier concentration and current density in the near-surface layer of a semiconductor are revealed for model axisymmetric structure corresponding to $0.35 \mu \mathrm{m}$ CMOS technology which determines dependence of Hall voltage from interaction of charge carriers with dielectric semiconductor interface. It was shown that sensitivity of field magnetic sensors can be widely regulated by controlling of MOSFET channel conductivity providing conditions for implementation of additional intellectual functions of magnetically sensitive devices.
\end{abstract}

Keywords - Hall element, Hall voltage, magnetic induction, space charge region, metal-oxide-semiconductor (MOS) structure, MOSFET, Hall field sensor, CMOS technology, silicon-on-insulator (SOI) structure, integrated circuit (IC).

\section{INTRODUCTION}

Since the 60-s of the last century up to this day majority of modern microelectronic devices are produced on the basis of silicon. This also applies to magnetically sensitive sensors and integrated circuits based on them. Significant advantage of silicon Hall sensors is ability to use them for production of basal silicon microelectronics technologies which ensures compatibility of sensor elements with interface electronics extending their range of performance and application possibilities through signal processing. In addition, use of modern CMOS technologies provides opportunities for implementation of Hall field sensors on the basis of metal-oxide-semiconductor structures (MOS) with surface inversion channel as well as the ones including integrated buried channel, as well as possibility of complete dielectric isolation of a sensor from the substrate and adjacent circuit elements due to formation of sensitive elements on silicon structures on insulator (SOI) $[1,2]$.

MOSFET Hall sensors belong to a class of semiconductor devices, the operation of which is significantly influenced by surface effects. [3,4]. The magnitude of Hall voltage in MOSFET Hall silicon elements with inversion channel and, respectively, the magnetic sensitivity is determined by the dependence of the mobility of the charge carriers from scattering at the $\mathrm{Si}-\mathrm{SiO}_{2}$ interface [5]. When developing such devices this problem can be solved in several ways. One of them is development of technological processes of obtaining $\mathrm{Si}$ $\mathrm{SiO}_{2}$ interface with minimum amount of scattering centers [6]. Another way is to choose structures with electronic conduction type providing maximum possible mobility of charge carriers as well as formation of an integrated buried channel with potential distribution near the $\mathrm{Si}-\mathrm{SiO}_{2}$ interface preventing contact of carriers with the surface [7].

In this manuscript magnetic sensitivity characteristics of Hall silicon field elements on the basis of MOSFET structures with buried channel are studied by means of methods of TCAD simulation. Studies were carried out on test samples with axisymmetric topological design developed using design standards $0.35 \mu \mathrm{m}$. Electrical modes for samples providing both inversion and enrichment of semiconductor-oxide interface margin were designed. Purpose of study was to identify field control ranges of functional characteristics of Hall MOSFET elements.

\section{SIMULATION PROCESS OF HALL MOSFET ELEMENT WITH BURIED CHANNEL}

To study characteristics of Hall element with buried channel and MOS field control in a wide range of control voltages (positive and negative) test sensor with topological design and structure formed according to design standards and electrical parameters of layers in compliance with design rules and instrumental technology specification XH035 of factory XFAB (Fig. 1) was modeled. Sensor after Hall MOS-transistor was formed on silicon p-type- conductivity substrate with specific resistance $15 \mathrm{Ohm} / \mathrm{cm}$. Buried channel of transistor at Si$\mathrm{SiO}_{2}$ interface is a $\mathrm{N}$-well (NWELL) with 3.5um depth. Its surface resistance was selected equal to $30 \mathrm{kOhm} / \mathrm{sq}$ in order to realize possibility of electrostatic state change of $\mathrm{N}$-well in a wide range. Electrostatic control of channel conduction is carried out by field electrode (Poly1) through a thin oxide $45 \mathrm{~nm}$ thick. Root square element configuration $(200 \times 200 \mu \mathrm{m})$ with dotted axisymmetric contacts $(n+$ regions, dimensions $5 \times 5 \mu \mathrm{m}$, depth $0.6 \mu \mathrm{m}$ 
and surface resistance $57 \mathrm{Ohm} / \mathrm{sq}$ ) was selected for simulation.

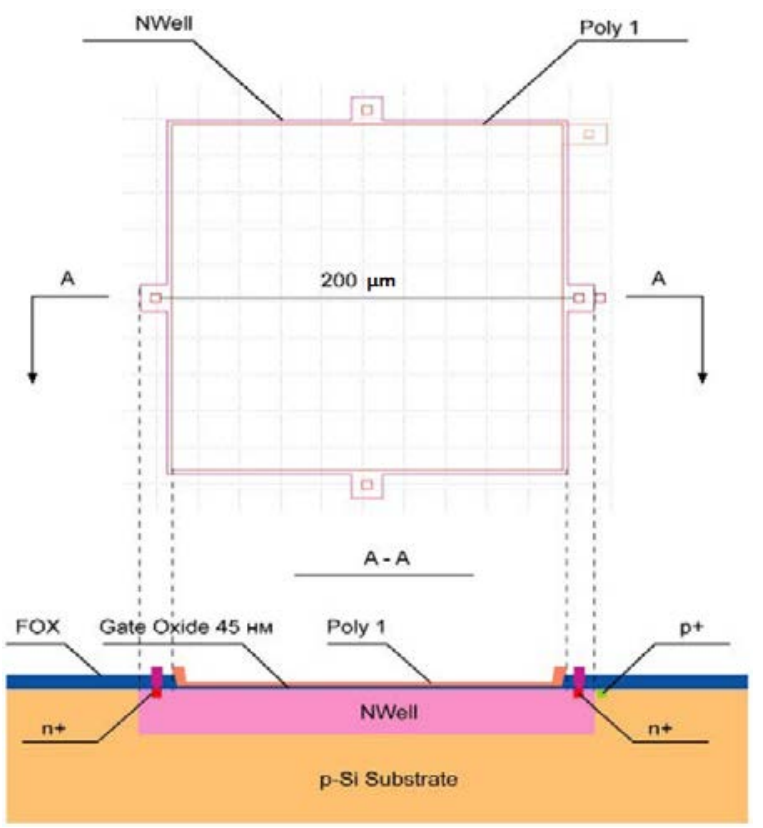

Fig. 1. Layout and structure of Hall MOS element with integrated channel

Simulation was performed with use of Synopsys Sentaurus TCAD software complex by finite element method (FE). Construction of three-dimensional model of Hall element was performed on the basis of technological parameters of the layers and developed technology; generation and adjustment of grid parameters for optimization of time and accuracy of calculation as well as result processing for construction of typical sensor dependencies were performed. Transfer processes of charge carriers were modeled within diffusion-drift model which included continuity equations for electrons and holes and Poisson equation. Recombination of charge carriers according to Shockley-Reed-Hall mechanism, namely, dependence of life expectancy of carriers from concentration of impurities resulting from direct correlation of recombination centers concentration with semiconductor impurity doping, as well as Auger recombination were taken into account. The used model also considered field dependence of electrons and holes mobility and changes in mobility and width of prohibited area with variation in impurity doping concentrations.

\section{RESULTS OF SIMULATION}

Figure 2 shows the output (a) and drain-gate (b) element characteristics.
Id, $\mu \mathrm{A}$

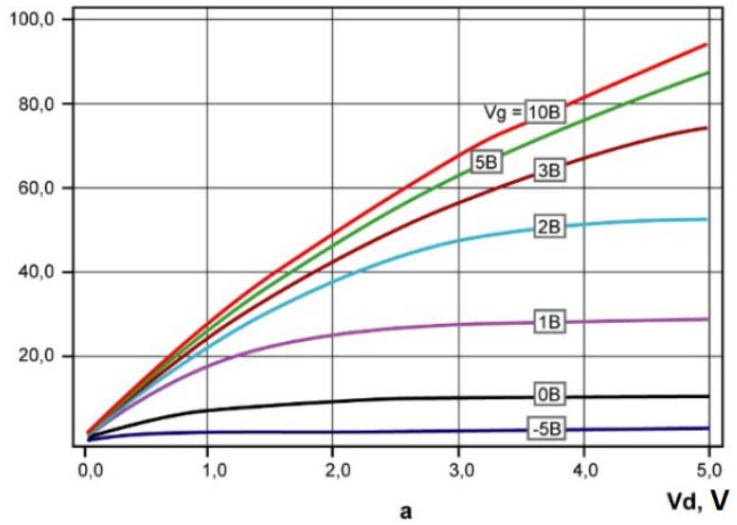

Id, $\mu \mathrm{A}$

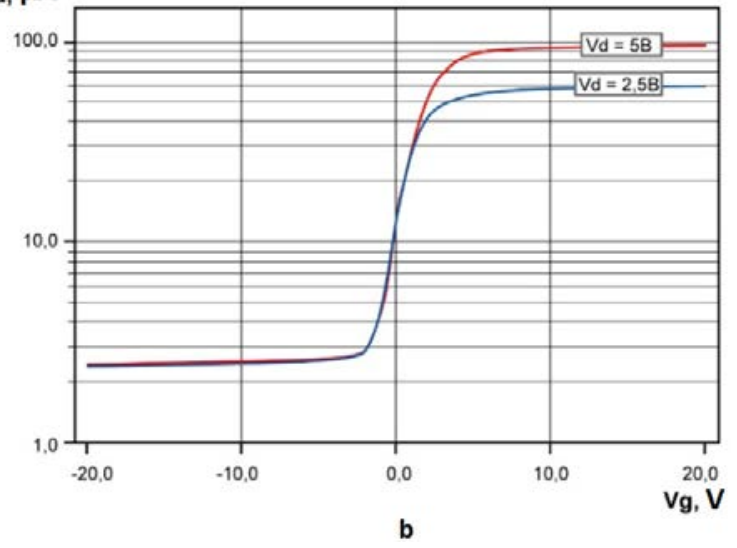

Fig. 2. The output (a) and drain-gate (b) characteristics of Hall MOS element with integrated channel

When potential of field electrode $V g$ changes from positive to negative values dielectric-semiconductor interface goes from a state of strong electron enrichment to conduction inversion, passing state of flat bands at $V g \sim$ 0 . This transition is illustrated in fig. 3 through dependence of the concentration distribution of free charge carriers (electrons and holes) along the depth of N-well.

Figure 3 shows that concentration of free charge carriers at dielectric-semiconductor interface of electrons with strong enrichment $(\mathrm{Vg}=+10 \mathrm{~V})$ as well as holes with strong inversion $(\mathrm{Vg}=-10 \mathrm{~V})$ reaches values $n, p \sim 5$. $10^{17} \mathrm{~cm}^{-3}$. It is clear that such cardinal change in channel conductivity when a strong enrichment is due to the conductivity of a thin (less than $1 \mu \mathrm{m}$ ) near-surface layer of a semiconductor with a high electron concentration, and with a strong inversion due to deep conductive layer with an electron concentration corresponding to $\mathrm{N}$-well doping level of $\left(N p \sim 10^{15} \mathrm{~cm}^{-3}\right)$ will render significant effect on magnetic characteristics of element. 


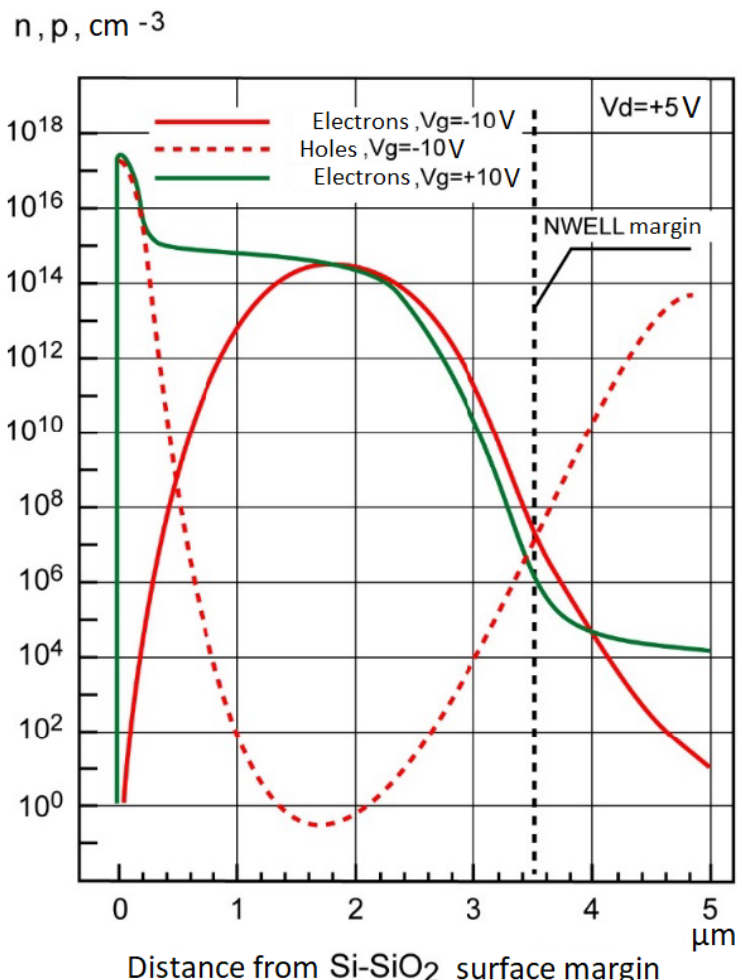

Fig. 3. Concentration distribution of free charge carriers (electrons and holes) along the depth of $\mathrm{N}$-well

Displacement of conduction channel from the surface into the $\mathrm{N}$-well when the surface passes from the enrichment to inversion is illustrated in fig. 4 which presents a 2d-illustration of dependencies of current density between source and drain of transistor vs distance from dielectric-semiconductor surface.
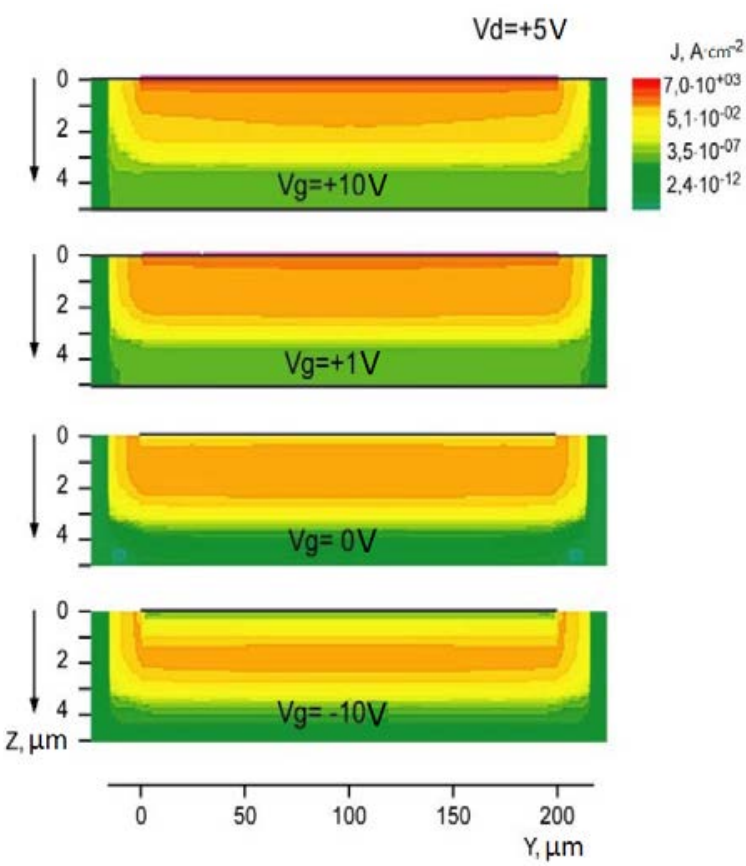

Fig. 4. Distribution of current density between source and drain of transistor at various values of field electrode potential
Magnetic sensitivity characteristics of simulated sensor depending on field electrode potential at two voltage values between the source and drain of transistor are presented in fig.5.
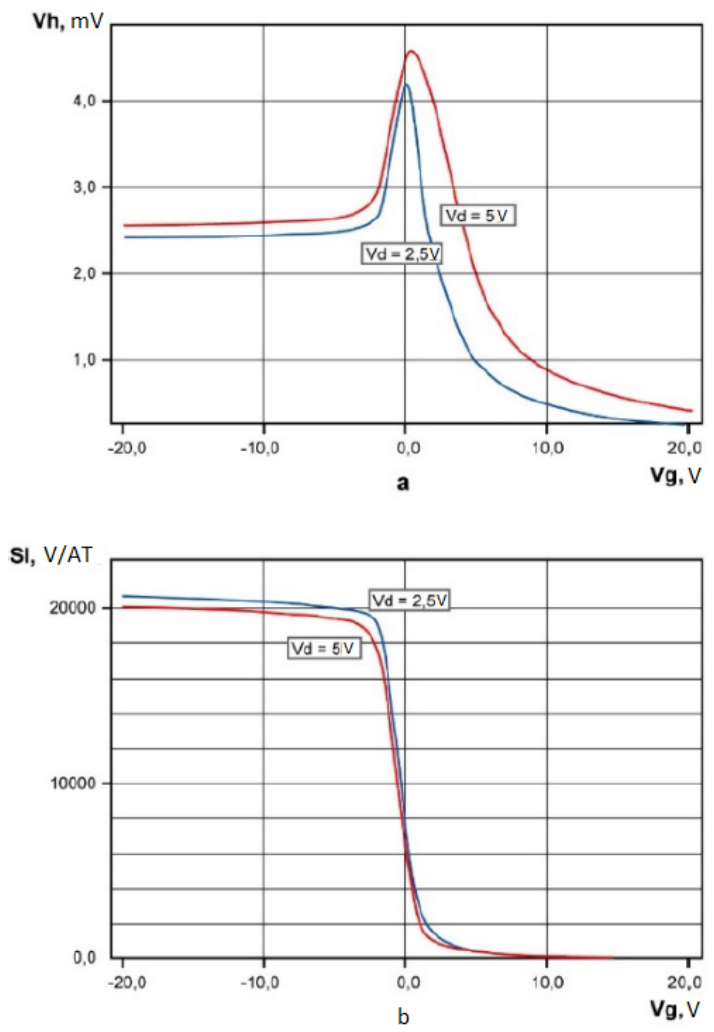

Fig. 5. Magnetic sensitivity characteristics of element: dependencies of Hall voltage (a) and magnetic sensitivity of current (b) from field electrode potential at $\mathrm{Vd}=5 \mathrm{~V}$ and $2,5 \mathrm{~V}$ $(\mathrm{B}=50 \mathrm{mT})$

Dependence of Hall voltage at constant supply voltage and variations of potential of field gate is determined by the following physical processes.

At negative values of a field electrode potential dielectricsemiconductor interface is in an inversion state with high concentration of holes on the surface of semiconductor, most of control potential declines on dielectrics, while current of channel is determined by conductivity of $\mathrm{N}$ well volume clipped by areas of space charge region (SCR) on the surface and at interface with p-substrate and is practically unchanged of $\mathrm{Vg}$ values up to flat areas potential. During transition from negative to positive values of field electrode potential semiconductor surface transitions through state of flat areas when conduction channel has maximum depth, not yet in contact with the surface, which ensures electron mobility corresponding to its volume value. In this condition field and concentration effects influencing reduction in mobility are minimal and Hall voltage has its maximum value.

With increasing positive values of field electrode potential surface of semiconductor transitions into a state of strong accumulation at which current flows through the 
channel on a thin near-surface layer, and electron mobility is significantly reduced due to effects of high concentration of free carriers and scattering at dielectricsemiconductor [3]. Therefore Hall voltage declines. Decreased electron mobility depending on their concentration at dielectric-semiconductor interface is illustrated by the graph shown in fig. 6 .

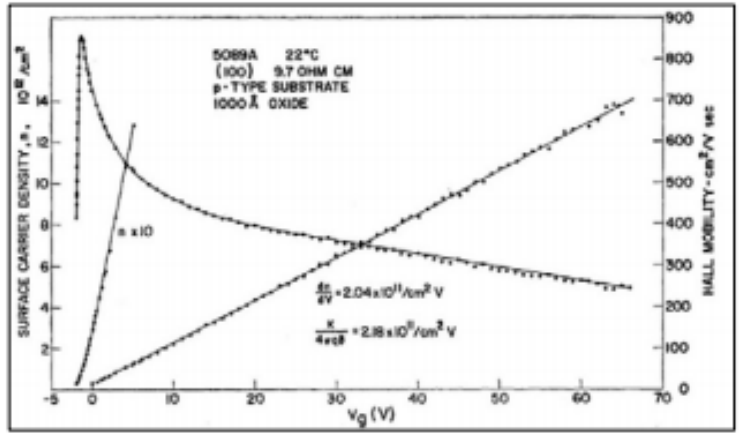

Fig. 6. Dependency of mobility of electrons in MOStransistor channel from gate voltage [3]

It should be clarified that the above statement is true for the case of quasi-stationary electrostatic state of nearsurface region of semiconductor which is realized through speeds of changes of field electrode potentials, lower rates of thermal generation of electron-hole pairs.

\section{CONCLUSION}

Results of simulation of MOSFET Hall element with buried N-channel of $200 \times 200 \mu \mathrm{m}^{2}$ with impurity doping concentration $\mathrm{Nd} \sim 10^{15} \mathrm{~cm}^{-3}$ and with working oxide of $45 \mathrm{~nm}$ presented in this manuscript showed that when the field control voltage changes from positive to negative values dielectric-semiconductor interface passes from high electron enrichment to conduction inversion. Strong enrichment conduction channel is formed as thin (less than $1 \mu \mathrm{m})$ near-surface layer of semiconductor with high concentration of electrons $\left(n \sim 5 \cdot 10^{17} \mathrm{~cm}^{-3}\right)$, and strong inversion - in the form of embedded conductive layer with concentration of electrons corresponding to a level of impurity doping of $\mathrm{N}$-well $\left(\mathrm{Nd} \sim 10^{15} \mathrm{~cm}^{-3}\right)$. In this case, changes of field potential in the range of $\pm 5 \mathrm{~V}$ provides possibility of controlled change of Hall voltage within $200 \%$ at maximum values $V_{\mathrm{H}} \sim 4.5 \mathrm{mV}$ and magnetic sensitivity of current at the level of $2000 \mathrm{~V} /(\mathrm{A} \cdot \mathrm{T})$.

\section{ACKNOWLEDGEMENTS}

Authors express deep gratitude to V.N. Mordkovich, Rashit Z. Khafizov and V.N. Anufriev for their helpful discussions.

\section{REFERENCES}

[1] Mordkovich V. N. Datchiki na osnove struktur «kremniy na izolyatore» (Sensors based on silicon-oninsulator structures) // Electronic Technics. Series 2. Semiconductor device. 2008. No. 2. P. 34-45. (in Russian)

[2] Leonov A.V., Mordkovich V.N., Pavluyk M.I. Kremieviy polevoy datchik Holla s rasshyrennym diapazonom rabochih temperatur (Silicon field Hall sensor with extended operating temperature range // Instruments and Experimental Techniques. 2016. No. 5. P. 104-108. (in Russian)

[3] F.F.Fang, A.B. Fowler. Transport Properties of Electrons in Inverted Silicon Surfaces // Physical Review. 1968. V. 169. P. 619-631.

[4] V.V. Pospelov, R.A. Suris, B. I. Fouks (Fuks), R.Z. Hafizov (Khafizov). Influence of Surface States on the Charge Transfer along the DielectricSemiconductor Interface // Proceedings of the 3rd international conference «Technology and application of charge coupled devices». 1976. P. 31-37.

[5] Zolotarev B.I., Pospelov V.V, Fetisov E.A., Khafizov R.Z. Issledovanie podvizhnosti neosnovnyh nositeley zaryada v inversionnyh kanalah MDP structur (Study of minority charge carriers mobility in inversion channels of MOS structures) // Microelectronics. 1974.V.3. No.5. P.413-417. (in Russian)

[6] Kandyba P.E., Zolotarev B.I., Khafizov R.Z. Vliyanie okisleniya $\mathrm{v}$ chlorsodezhaschey srede na rasseyanie $\mathrm{v}$ inversionnyh kanalah MDP structur (Effect of oxidation in a chlorine-containing environment on scattering in inversion channels of MOS structures // Microelectronics. 1977. V.6. No. 2. P. 184-188. (in Russian)

[7] Pospelov V.V., Fuks B. I., Khafizov R.Z. Issledovanie khollovskoy podvizhnosti v skrytyh kanalah MDP structur (Investigation of hall mobility in buried channels of MOS structures) // Sb. Physical Processes in MOS structures. 1976. P. 15-17. (in Russian) 